\title{
Multiple forms of mitochondrial DNA in higher plants
}

from Thomas D. Fox

THE study of the structure of the mitochondrial genomes of higher plants is a daunting task. Simply in terms of size there are problems enough - the genomes can contain from about 200 kilobases $(\mathrm{kb})$ to over $2,000 \mathrm{~kb}$ of primarily unique sequence, according to species. In comparison, human mitochrondrial DNA, which appears to code for roughly the same number of products, is only $16.5 \mathrm{~kb}$ long. Worse yet, electron microscopy of plant mitochondrial DNA reveals a complex assortment of differently sized circular and linear molecules, and restriction digests contain fragments in sub-stoichiometric amounts, suggesting a heterogeneous structure (for a review see ref.1).

Some semblance of order in this situation has now been provided by the restriction mapping studies of Palmer and Shields $^{2}$, reported in this issue of Nature (see p.437). Their results suggest that plant mitochondrial genomes are carried on discrete circular molecules which are derived from each other by recombination.

Chromosome walks along the mitochondrial DNA of Brassica campestris (Chinese cabbage, turnip) led around three differently sized circles. The largest, $218 \mathrm{~kb}$ long, contains the entire sequence complexity of the Brassica mitochondrial genome. This 'master chromosome' contains a major direct repeat of about $2 \mathrm{~kb}$, whose elements are separated by $135 \mathrm{~kb}$ on one side and $83 \mathrm{~kb}$ on the other. The other two circles are 135 and $83 \mathrm{~kb}$ in size and each contains the corresponding sequences present between the repeats of the master chromosome and a single copy of the repeated element. (Other arrangements, such as dimers of the $218 \mathrm{~kb}$ circle, are consistent with the mapping data perse but fail to explain the stoichiometries observed for fragments containing the repeats and surrounding unique DNA.) Clearly, a simple way to account for these

\section{0 years ago}

BULLETIN No. 3 of the Entomological Division of the U.S. Department of Agriculture (Washington, 1883), when stripped of the "redtape" that appears to be even more necessary on official documents in the States than it is in this country, is of more than usual interest. The notorious "army-worm" appears in a new character, viz, as destructive to cranberries, which form an important feature in the production of the States. A long chapter is devoted to the "cotton-worm" in which (in addition to interesting biological information) elaborate contrivances for distributing arsenical solutions are described.

From Nature 29, 344, 7 February 1884. species is to assume that they are related to each other by homologous recombination between repeated elements.

As Palmer and Shields point out, this relatively simple tripartite picture may turn out upon further study to be complicated by the presence of other minor species. One would, for example, expect the presence of dimers of the $83 \mathrm{~kb}$ and $135 \mathrm{~kb}$ circles to be present. Furthermore, Palmer and Shields detected, but did not map, other minor repeated sequences in Brassica mitochondrial DNA which may also serve as sites for recombination.

Mapping studies on the much larger mitochondrial genome of maize by Lonsdale and co-workers at the Plant Breeding Institute and University of Cambridge (personal communication) have indeed revealed a similar but more complex picture. They have mapped a maize mitochondrial DNA master chromosome of $570 \mathrm{~kb}$ and located six pairs of repeated elements within it: five direct repeats and one inverted repeat. In addition, six other smaller circular maps, ranging in size from 47 to $503 \mathrm{~kb}$, were generated and could be derived from the master chromosome by recombination between pairs of repeated elements. These smaller circular maps seem to correspond well in size to circles identified in maize mitochondrial DNA by electron microscopy $^{3}$. Thus the presence of multiple circular species of DNA, related by recombination between repeated elements, may be a general feature of higher-plant mitochondrial genomes.

The study of recombination in plant mitochondrial DNA has been hampered both by the lack of genetic markers and because mitochondrial DNA is maternally inherited. Nevertheless, evidence for recombination has been obtained by somatic cell hybridization of strains differing in polymorphic mitochondrial DNA restriction fragments ${ }^{4-6}$. The hybrids typically contain new combinations of parental fragment types, as might be expected from the assortment of multiple circular DNAs during mitotic growth. In addition, many hybrids contain novel fragments not found in either parent, which most probably arise as a result of true crossing-over. Complete restriction maps of plant mitochondrial DNAs will allow the detailed analysis of recombination in somatic cell hybrids.

Whether plant mitochondria contain a general recombination system, such as that present in yeast mitochondria, is not yet clear. They may contain site-specific recombination systems which only function at some repeated elements - a possibility suggested by the finding of repeated elements in maize mitochondria DNA that are not surrounded by the expected recombinant set of restriction fragments (D.M. Lonsdale, personal communication). Site-specific recombination would tend to limit the number of different circles that could be generated from a master chromosome containing many repeats. (The large number of linear molecules in preparations of mitochondrial DNA from plants, as well as yeast, are assumed by most workers to be the result of in vitro degradation. Perhaps some of these linear molecules are recombination intermediates present in vivo.)

Progress in identifying plant mitochondrial genes through their homology with genes of other organisms will soon make it possible to see whether the arrangement of genes is conserved, as in animals, or not, as in fungi. Using the restriction maps of the maize genome, D.M. Lonsdale and C.J. Leaver of the University of Edinburgh (personal communication) have already shown that the genes coding for cytochrome oxidase subunit I, apocytochrome $b$ and a protein homologous to that encoded by the human unassigned reading frame $U R F 1$ are present in a cluster. The cluster also contains sequences derived from chloroplast DNA containing what appear to be pseudogenes for chloroplast 16S rRNA $^{7}$ and the large subunit of ribulose bisphosphate carboxylase ${ }^{8}$. About $200 \mathrm{~kb}$ away is another gene, for cytochrome oxidase subunit $\mathrm{II}^{9}$, and midway between them, the rRNA genes.

Comparisons between species such as Brassica and maize will also help give some clues as to why the majority of plant mitochondrial DNA sequences appear not to code for useful products. That chloroplast DNA sequences ${ }^{7,8}$ are found in maize mitochondrial DNA led Lonsdale to suggest that the ability to take up foreign DNA could in part account for the large and variable sizes of plant mitochondrial genomes. It will be interesting to see how true this is of other species, and whether bona fide nuclear DNA sequences also turn up in plant mitochondria.

Thomas D. Fox is at the Section of Genetics and Development, Cornell University, Ithaca, New York 14853.

1. Leaver, C.J. \& Gray, M.W. A. Rev. Pl. Physiol. 33, 373 (1982).

2. Palmer, J.D. \& Shields, C.R. Nature 307, 437 (1983).

3. Levings, C.S. in Extrachromosomal DNA, ICN-UCLA Symposium on Molecular and Cellular Biology (eds
Cummings, D., Borst, P., Dawid, I., Weissman, S. \& Fox, C.F.) 63 (1979).

4. Belliard, G., Vedel, F. \& Pelletier, G. Nature 281, 401 (1979).

5. Nagy, F., Torok, 1. \& Maliga, P. Molec. gen. Genet. 183 , 437 (1981).

6. Boeshore, M.L., Lifshitz, I., Hanson, M.R. \& Shamay, L Molec. gen. Genet. 190, 459 (1983).

7. Stern, D.B. \& Lonsdale, D.M. Nature 229, 698 (1982)

8. Lonsdale, D.M., Hodge, T.P., Howe, C.J. \& Stern, D.B. Cell 34, 1007 (1983)

9. Fox, T.D. \& Ledaver, C.J. Cell 26, 315 (1981) 